\title{
Erratum to: Detection of transgenes in three genetically modified rice lines by fluorescence in situ hybridization
}

\author{
Hye Mi Park - Eun Jin Jeon - Nomar Espinosa Waminal - Kong Sik Shin - Soon Jong Kweon • \\ Beom-Seok Park - Seok Cheol Suh $\cdot$ Hyun Hee Kim
}

The Genetics Society of Korea and Springer 2011

Erratum to: Genes \& Genomics (2010) 32: 527-531

DOI $10.1007 / \mathrm{s} 13258-010-0064-\mathrm{z}$

The original version of this article contained an error in the Acknowledgements which should be corrected as follow.

Acknowledgements We would like to give thanks to reviewers and editors with their comments and recommendations which were very significant in improving and enhancing our manuscript. This work was supported by the Rural Development Administration of Korea (Biogreen21 Program code \#20080401034032, and PJ006754), and by the Ministry of Education, Science and Technology, Korea, through the Crop Functional Genomics Center (CG2141 to S.C. Suh).

The online version of the original article can be found under doi:10.1007/s13258-010-0064-z.

H. M. Park · E. J. Jeon · N. E. Waminal · H. H. Kim( $(\bowtie)$ Plant Biotechnology Institute, Sahmyook University, Seoul 139-742, Korea

e-mail: kimhh@syu.ac.kr

K. S. Shin · S. J. Kweon · B. S. Park · S. C. Suh

Bio-safety Division, National Academy of Agricultural Science, RDA, Suwon 441-707, Korea 